\title{
The Relation of Body Fats, Anthropometric Factor and Physiological Functions of Iranian Female National Judo Team
}

\author{
Parvaneh Nazar Ali \\ Faculty of Sport Science, Alzahra University, Tehran Iran \\ E-mail: nazarali@yahoo.com
}

Parichehr Hanachi (Coresponding author)

Faculty of Basic Science, Biology Department, Biochemistry unite, Alzahra University, Tehran Iran

Tel: 98-21-8804-9809_E-mail: Hanachi_wre@yahoo.com

\author{
Najmeh Rezaei Nejad \\ Faculty of Sport Science, Alzahra University, Tehran Iran \\ E-mail: Najmeh_rn@yahoo.com
}

\begin{abstract}
Both the IJF (International Judo Federation) and the IOC (International Olympic Committee) regulations require athletes to compete in set weight categories. Competitors are matched by weight divisions, thus players demonstrate relatively low levels of body fat with a high strength to mass ratio, and therefore the purpose of this study was to investigate the relation of body fats, anthropometric factors and physiological functions of Iranian female national judo players. The participants of this study were eight players of Iranian Judo national team (age, $22.5 \pm 2.4 \mathrm{yr}$; weight, $66.01 \pm 6.4 \mathrm{~kg}$; height, $165 \pm 6.6 \mathrm{~cm}$ ). The physiological profile was composed of aerobic (maximal test) and anaerobic power (ergo amp test). For anthropometric and body composition profiles, height, weights, body fat percentage, body mass index (BMI), waist hip ratio (WHR) were measured. Correlations were found between weight and body fat percentage and WHR. However negative correlation was found between aerobic and anaerobic power. Also positive correlation was found between BMI and lean body mass. Finding has showed judo players in this study, were almost favorite in terms of aerobics power and weight. The judo players who presenting higher aerobic power present a better performance in high-intensity intermittent activities; judo players with larger circumferences present higher absolute maximal strength, but this relation was not significant when strength was expressed relative to body weight. While these variables do not necessarily predict performance in a sport where technique and tactics are essential elements for success, they may provide some goals for developing judo players.
\end{abstract}

Keywords: Anthropometric factors, Body fats, Judo player

\section{Introduction}

Judo is Japanese art and Olympic sport in which, besides technical skill and tactical strategies, conditional characteristics are also indispensable for success in competition and for training (Franchini et al, 2005).

Competitive judo can be described as a combative, high intensity sport in which the athlete attempts to throw the opponent onto his back or to control him during groundwork combat. Both attempts depend on specific techniques and tactical skills with the support of good physical fitness (Thomas et al, 1989). Since 2003 the format of international judo competition has been one continuous 5 -min period, which can be complemented by extra time until one athlete scores or to the end of the new 5-min period (Emerson et al, 2007). The typical time structure is $30 \mathrm{~s}$ of activity with a $10 \mathrm{~s}$ interval (Castarlenas and Planas, 1997; Sikorski et al, 1987). The anaerobic system provides the short, quick, all-out bursts of maximal power during the match, while the aerobic system contributes to the athlete's ability to sustain effort for the duration of the combat and to recover during the brief periods of rest or reduced effort (Franchini et al 2003; Muramatsu et al 1994). Physiological testing is commonly used to assess the overall fitness level of the athletes and to set guidelines for individualized training (Emerson et al 2007). Some physical fitness and anthropometrical variables are considered requisites for high performance in judo competition (Sikorski et al, 1987; Thomas et al, 1989). 
As judo is a weight-classified sport, it has been suggested that high level judo players should have low body fat (Kubo et al, 2006). It has been suggested that percent body fat may be a discriminator for success. Callister et al (1991) found that more successful male players (those with more international success or competition points) maintained lower body fat percentages. Although this may be true, it may just be a reflection of physiological adaptations to long-term judo training. A recent study (Kubo et al, 2006) demonstrated that judo athletes who participated in the Olympic Games or Asian games had significantly larger fat-free mass than university judo athletes who did not participate in intercollegiate competitions. In fact, the muscle thickness normalized to the height of the individual was larger in judo players at the international level than in those at the university level.

From the physiological viewpoint, anaerobic power and capacity, strength, and aerobic power have been considered the main characteristics to be developed by judo players (Kubo et al, 2006).

Although these aspects are thought to be important to judo performance, few studies compared high level with lower level judo players concerning physical fitness. Borkowsky et al. (2001) did not find any difference in lower-body Wingate and $\mathrm{VO}_{2}$ max values among Polish championship winners and second and third placers.

Therefore, the purpose of the present study was to investigate the relation of body fats, anthropometric factors and physiological functions of Iranian female national judo players.

\section{Materials and Methods}

\subsection{Subjects and research design}

Eight Iranian elite judo players, with more than 8 years of judo practice, participated in this study. Athletes were assessed fifty days before the definition of teams that would participate in Asian competitions in 2009.

\subsection{Body composition analyzer}

Height was measured in the upright position with stadiometer. Weight, body fat percentage, lean body mass, BMI and WHR measured with body composition analyzer according to Latiffah and Hanachi , 2008, methods.

\subsection{Aerobic power measurement}

Aerobic power was measured $\left(\mathrm{VO}_{2 \max }\right)$ with Cosmed $\mathrm{K}_{4} \mathrm{~b}_{2}$ portable oxygen analyzer $\left(\mathrm{K}_{4} \mathrm{~b}_{2}\right.$, COSMED, Italy) after performed an incremental work rate test which was started with $6 \mathrm{~km} . \mathrm{h}-1$ and increased $1 \mathrm{~km} . \mathrm{h}-1$ every 1 minutes until the players were exhausted.

\subsection{Anaerobic power measurement}

Anaerobic power was measured with Ergojump test (vertical jump test and the line drill) the subjects stood on a rubber-coated contact platform connected by a cable to a digital timer that recorded the flight time of all jumps. The timer was triggered by the release of the subject's feet from the platform, and stopped at the moment of touchdown. An anaerobic power jump test (APJT) was also measured by using a 15-second vertical jump test on the Ergojump. Anaerobic power was calculated from the sum of the flight time and the number of jumps executed during the exercise time period (Hoffman et al, 2000) however the velocity was measured with 40 yard test (Cressey et al, 2007).

\subsection{Statistical analysis}

All statistical analyses were performed with using SPSS 10.0 (Statistical Package for Social Science). Descriptive statistics including means and SDs for the outcome variables of interest were computed. Pearson product moment correlations were used to determine the degree of association among selected variables. In light of multiple comparisons statistical significance were assigned at $\mathrm{p}<0.05$ for all analysis.

\section{Results}

Anthropometric and body composition characteristics major anthropometric and body composition characteristics of the judo team are shown in Table 1.

Table 2 showed subjects have anaerobic power $(30.0 \pm 7.11 \mathrm{~cm})$, agility $(10.46 \pm 0.41 \mathrm{~second})$, aerobic power $\left(47.88 \pm 4.1 \mathrm{ml} / \mathrm{kg}^{-1} / \mathrm{min}^{-1}\right)$, velocity $(6.60 \pm 0.281$ second) Wingate hand and feet $(1.4838 \mathrm{E} 2 \pm 26.602$, $2.4975 \mathrm{E} 2 \pm 35.418 \mathrm{w} \cdot \mathrm{kg}^{-1}$ ) respectively.

Table 3 showed the relation between body fat and $\mathrm{VO}_{2 \max }$, fat and velocity, weight and $\mathrm{VO} 2_{\max }$. The finding shows that anaerobic power and fat were negative correlation $(\mathrm{r}=-0.46)$. However between weight and velocity $(\mathrm{r}$ $=0.29)$, anaerobic power and $\mathrm{VO}_{2 \max }(\mathrm{r}=0.85)$ the relation was positive. 


\section{Discussion}

In fact, the body fat percentage values found for subjects in this study was not similar to those found in other studies with national teams or high-level judo players, Moriwaki (2000) showed that the elite Judaist in Japan had $23.34 \%$ body fat percentage. Investigate showed that judoists with lower body fat percentage, higher anaerobic performance in the Special Judo Fitness, tend to execute more attacks during combat, probably due to a better metabolic adaptation to combat requirements (Franchini,2005). The $\mathrm{VO} 2_{\max }$ estimated in this study was near the lower limits remarked for high-level judo players than other research, for example Callister (1990) showed that elite American Judaist had $53.2 \mathrm{ml} / \mathrm{kg} / \mathrm{min}$ for aerobic power, also Little (1991)and Tumilty (1986) showed that elite Judaist Canadian and Australian had 57.62 and $53.2 \mathrm{ml} / \mathrm{kg} / \mathrm{min}$ for $\mathrm{VO} 2_{\max }$ respectively. This result can be interpreted as indicating a need to improve the aerobic fitness of the groups studied in the present investigation.

Several study showed that most judo players presented $\mathrm{VO} 2_{\max }$ values between 50 and $60 \mathrm{ml} / \mathrm{kg} / \mathrm{min}$, even using different protocols and equipment (Emerson et al, 2007). However, the importance of aerobic power to judo performance is controversial. While some authors did not find significant differences in $\mathrm{VO} 2_{\max }$ between elite and non-elite judo players (Borkowsky et al, 2001; Franchini et al, 2005), some results indicate that aerobic power has a positive influence in high-intensity intermittent exercise (Gariod et al, 1995).

Gariod et al. (1995) found that judo players with a higher $\mathrm{VO}_{2 \max }$ presented a faster $\mathrm{CP}$ re-synthesis compared with judo players with a lower $\mathrm{VO}_{2 \max }$. It has been suggested that judo players with a higher $\mathrm{VO}_{2 \max }$ would have an advantage in a period of combat with maximal duration $(5-\mathrm{min})$ because the same absolute supramaximum effort would represent a lower relative intensity compared to an athlete with a lower vo2max (Muramatsu, et al, 1994).

The positive influence of a higher $\mathrm{VO}_{2 \max }$ on intermittent exercise performance is partially confirmed by the positive correlation between this variable and the number of throws and the index in the SJFT for the groups studied (Emerson et al, 2007). However, other result of this study was negative correlation between relative $\mathrm{VO}_{2 \max }$ and judo players' weight. Thomas et al. (1989) had also remarked a negative correlation between relative $\mathrm{VO}_{2 \max }$ and judo players' weight. Nevertheless, in our study it seems clear that a large part of this relation can be explained by the high fat percentage. Also the negative influence of body fat on motor performance observed in Franchini. (2005) and Nakajima (1998) studied. Also results showed a negative influence of body fat on aerobic power in female judo players that agree with Nakajima et al. (1998) results. According to Cooper and Sjft tests the higher fat percentage caused lower performance in activities which involving body displacement However, judo players presenting higher aerobic power present a better performance in high-intensity intermittent activities; While these variables did not necessarily predict performance in a sport where technique and tactics were essential elements for success.

\section{Conclusion}

The data provided the judo player with information on where training might be directed to compensate for areas where the athlete was below average for successful judo players. A judo player who does not match the ideal profile can still succeed through improved or superior techniques and tactics. Other variables (psychological factors, for example) should be studied to verify which factors can discriminate properly first placers and reserves at the national level.

\section{Acknowledgment}

The author would like to thanks the Faculty of Sport Sciences Alzahra University, Tehran-Iran. for funding this study:

\section{References}

Borkowsky L, Faff J, Starczewska-Czapowska J. (2001). Evaluation of the aerobic and anaerobic fitness in judoists from the Polish national team. Biol Sport, 18: 107-111.

Callister R, Callister RJ, Fleck SJ, Dudley GA. (1990). Physiological and performance responses to overtraining in elite judo athletes. Med Sci Sports Exerc, 22: 816-824.

Callister R, Callister RJ, Staron RS, Fleck SJ, Tesch P, Dudley GA. (1991). Physiological characteristics of elite Judo athletes. Int J Sports Med ,12: 196-203

Castarlenas JL, Planas A. (1997). Studio de la structure temporal del combate de judo. Apunts, 47: 32-39

Cressey. E. M, West. C. A, Tiberio. D.P, Kraemer.W. J, Maresh. C. M. (2007). The effects of ten weeks of lower-body unstable surface training on markers of athletics performance. Journal of Strength and Conditioning 
Research, 561:21, 2.

Emerson Franchini, Alexandre Velly Nunes, Josué Morisson Moraes and Fabrício Boscolo Del Vecchio. (2007). Physical Fitness and Anthropometrical Profile of the Brazilian Male Judo Team. J Physiol Anthropol, 26(2): 59-67.

Franchini E, Takito MY, Nakamura FY, Matsushigue KA, Kiss MAPD. (2003). Effects of recovery type after a judo combat on blood lactate removal and performance in an intermittent anaerobic task. $J$ Sports Med Phys Fitness, 43: 424-431.

Franchini E, Takito MY, Kiss MAPDM, Sterkowicz S. (2005). Physical fitness and anthropometric differences between elite and nonelite judo players. Biol Sport, 22: 315-328.

Gariod L, Favre-Juvin A, Novel V, Reutenauer H, Majean H, Rossi A. (1995). Evaluation du profit energetique des judokas par spectroscopie RMN duP31. Sci Sports, 10: 201-207.

Hoffman, J. R. Epstnein. S, Einbinder, M and Weinstein, Y. (2000). A Comparison between the Wingate Anaerobic Power Test to Both Vertical Jump and Line Drill Tests in Basketball Players. Journal of Strength and Conditioning Research, 14(3): 261-264.

Kubo J, Chishaki T, Nakamura N, Muramatsu T, Yamamoto Y, Ito M, Saitou H, Kukidome T. (2006). Differences in fat-free mass and muscle thicknesses at various sites according to performance level among judo athletes. J Strength Cond Res, 20(3): 654-657.

Latiffah L, Hanachi P. (2008). To investigate the relation of hypertension and anthropometric measurement. Journal Applied Science, 8(21): 3963-3968, 2008.

Little NG. (1991). Physical performance attributes of Junior and Senior women, Juvenile, Junior and Senior men judokas. J Sports Med Phys Fitness, 31: 510-520.

Moriwaki.Y, Oizumi.Y, Koyama.Y. (2000). Fandamental physical fitness in female. The Annual Reports of Health, Phyical Education and Sport Science, 19:71-78.

Muramatsu S, Horiyasu T, Sato SI, Hattori Y, Yanagisawa H, Onozawa K, Tezuka M. (1994). The relationship between aerobic capacity and peak power during intermittent anaerobic exercise of judo athletes. Bulletin of the Association for the Scientific Study on Judo Kodokan ,8: 151-160.

Nakajima T, Wakayama H, Iida E, Matsumoto D. (1998). The Relationship between body fat and basic physical fitness for female athletes (part 2). In National Judo Conference International Research Symposium Annals. United States Olympic Training Center, Colorado Springs.

Sikorski W, Mickiewitz G, Majle B, Laksa C. (1987). Structure of the contest and work capacity of the Judaist. In Proceedings of the International Congress on Judo: Contemporary Problems of Training and Judo Contest. Warsaw: Spala-Poland: 58-65.

Thomas SG, Cox MH, Legal YM, Verde TJ, Smith HK. (1989). Physiological profiles of the Canadian National Judo Team. Can J Sport Sci, 14: 142-147.

Tumilty DM, Hahn AG, Telford RD. (1986). A physiological profile of well-trained male judo players. In Procceedings of the VIII Commonwealth and International Conference on Sport, Physical Education, Dance, Recreation, and Health. London, E e F.N. Spon: 3-10. 
Table 1. The anthropometric and body composition measurement of the respondent

\begin{tabular}{|c|c|}
\hline Variables & Control $(n=8)$ \\
\hline Age(Year) & $22.5 \pm 2.4$ \\
\hline $\operatorname{High}(\mathrm{cm})$ & $165 \pm 6.6$ \\
\hline Weight $(\mathrm{Kg})$ & $66.01 \pm 6.4$ \\
\hline BMI $(\mathrm{kg} / \mathrm{m} 2)$ & $24.1 \pm 3.3$ \\
\hline Lean mass (kg) & $47.1 \pm 4.9$ \\
\hline Body fat (\%) & $23 \pm 4.4$ \\
\hline
\end{tabular}

Data were presented as mean and SD.

Table 2. Physiological characteristics and anaerobic power of judo players (mean $\pm \mathrm{SD}$ )

\begin{tabular}{ll}
\hline Variables (n=8) & Mean, SD \\
\hline Anaerobic power (Vertical jump height) $(\mathrm{cm})$ & $30.0 \pm 7.11$ \\
Agility (Second) & $10.46 \pm 0.41$ \\
Flexibility (Degree) & $41.75 \pm 3.44$ \\
Wingate (hand)(w.kg ${ }^{-1)}$ & $1.4838 \mathrm{E} 2 \pm 26.602$ \\
Wingate (feet) (w. $\mathrm{kg}^{-1)}$ & $2.4975 \mathrm{E} 2 \pm 35.418$ \\
Velocity (Second) & $6.60 \pm 0.281$ \\
VO2max (ml.kg- $\left.\cdot \mathrm{min}^{-1}\right)$ & $47.88 \pm 4.1$ \\
\hline
\end{tabular}

Data were presented as mean and SD.

Table 3. Relation between the physiological characteristics, anaerobic power, anthropometric and body composition of the respondent

\begin{tabular}{llllll}
\hline & Fat & VO2max & weight & velocity & \multicolumn{1}{c}{$\begin{array}{c}\text { Anaerobic } \\
\text { power }\end{array}$} \\
\hline Body Fat & - & $\mathrm{R}=-0 / 63$ & $\mathrm{R}=0 / 75^{*}$ & $\mathrm{R}=0 / 47^{*}$ & $\mathrm{R}=-0 / 69^{*}$ \\
& & $\mathrm{P}=0 / 002$ & $\mathrm{P}=0 / 00$ & $\mathrm{P}=0 / 02$ & $\mathrm{P}=0 / 000$ \\
VO2ma & $\mathrm{R}=-0 / 63^{*}$ & - & $\mathrm{R}=-0 / 36$ & $\mathrm{R}=-0 / 65$ & \\
& $\mathrm{P}=0 / 002$ & & $\mathrm{P}=0 / 09$ & $\mathrm{P}=0 / 46$ & \\
Weight & $\mathrm{R}=0 / 75^{*}$ & $\mathrm{R}=-0 / 36$ & - & $\mathrm{R}=0 / 675^{*}$ & $\mathrm{R}=-0 / 566^{*}$ \\
& $\mathrm{P}=0 / 00$ & $\mathrm{P}=0 / 09$ & & $\mathrm{P}=0 / 001$ & $\mathrm{P}=0 / 006$ \\
& & & & & \\
\hline
\end{tabular}

*. Correlation was significant at the 0.05 level 